\title{
Studies on biochemical mechanism of resistance for the management of Marssonina leaf blotch of apple caused by Marssonina coronaria (Ellis \& J. J. Davis) J. J. Davis
}

\author{
S. Phurailatpam* and J. N. Sharma \\ Department of Plant Pathology, College of Horticulture, Dr. Y.S. Parmar University of Horticulture and Forestry, \\ Solan-173 230 (Himachal Pradesh), INDIA \\ *Corresponding author. E-mail: Sumitrapathology@gmail.com
}

Received: February 13, 2015; Revised received: July 22, 2015; Accepted: September 11, 2015

\begin{abstract}
To study the mechanism of resistance developed in three different cultivars of apple viz; Starking Delicious, Tydeman's Early Worcester and Granny Smith against Marssonina coronaria, after treatment with SAR inducing chemicals salicylic acid (SA), dipotassium phosphate $\left(\mathrm{K}_{2} \mathrm{HPO}_{4}\right)$ and acibenzolar-S-methyl (ASM) contents of total phenol, reducing sugar, non -reducing sugar and activities of polyphenol oxidase (PPO), and peroxidase (POD) were assayed at three sampling periods (48,72 and 96 hours). The results revealed that SA treated leaves of cultivar Granny Smith recorded highest amount of phenol $(49,53.66,57.33 \mathrm{mg} / \mathrm{g})$, reducing sugar $(16,16.33,17.66 \mathrm{mg} / \mathrm{g})$, non-reducing sugar $(2.90,3.13,3.53 \mathrm{mg} / \mathrm{g})$ content, peroxidase $(30,29.33,36)$ and polyphenol $(26,30,34)$ activity in all the sampling intervals followed $\mathrm{ASM}$ and $\mathrm{K}_{2} \mathrm{HPO}_{4}$ treated plants. When compared among the cultivars maximum production was observed highest in cultivar Granny Smith which was followed by cultivars Tydeman's Early Worcester and Starking Delicious. The present study showed that application of systemic acquired resistance (SAR) chemical can induce resistance in apple plants against Marssonina blotch caused by $M$. coronaria showing strong correlation between the ability of elicitors to enhanced plant disease resistance and elicitation of defence related enzymes. Thus, using SAR chemicals to induce resistance to apple against Marssonina blotch caused by $M$. coronaria, may provide a practical supplement to an environmentally friendly disease management when it is combined with appropriate integrated disease management practices.
\end{abstract}

Keywords: Non-reducing sugars, Peroxidase, Polyphenol oxidase, Reducing sugars, Total phenols

\section{INTRODUCTION}

Marssonina blotch caused by Marssonina coronaria (Ellis \& J.J. Davis) J.J. Davis is one of the most devastating diseases of apple in India and other apple producing countries (Lee et al., 2011). The disease not only reduces the photosynthetic area, fruit size, fruit colour and fruit quality but also affects the productivity (Harada et al., 1974; Sharma and Bhardwaj, 2003). The disease can be kept at low levels by following protective fungicidal sprays at short intervals during the growing season. This practice is in vogue in India also, particularly in Himachal Pradesh, where protective fungicidal sprays programme is adopted every year to keep the disease under check (Sharma and Gautam, 1997; Sharma and Kaul, 1996). But this approach may often lead to fungicide wastage particularly when weather conditions are not congenial for disease development. On the other hand, however, favourable weather conditions might result in high build up of the disease pressure making it compulsory to carry on fungicidal sprays at short intervals for effective disease control which will result in increased cost of production apart from added environmental pollution.
However, exploitation of host resistance by application of induced resistance chemicals would be an ideal approach in the context of subsistence farming of resource-limited regions of the world. Resistance to pathogens is associated with the accumulation of enzymes, antibiotics and inhibitors. Salicylic acid is a natural phenolic compound present in many plants and is an important component in the signal transduction pathway and is involved in local and systemic resistance to pathogens (Delaney et al., 1995 and Maleck et al., 2000).

Phenolic compounds are a chemically diverse and biologically important group of secondary metabolites. In apple trees, these compounds are involved in natural defence reactions against various diseases (Slatnar et al., 2010; Dao et al., 2011). Their rapid accumulation at the infection site limits the development of the pathogen, potentially isolating it at the original site of ingress (Nicholson and Hammerschmidt, 1992). When microbes invade plant cells, polyphenol oxidases are involved in the oxidation of polyphenols into quinones (Soliva et al., 2001). Peroxidases participate in wallbuilding processes, e.g., oxidation of phenols, and the suberization and lignification of host cells during the 
defence reaction against pathogenic agents (Mohammadi and Kazemi, 2002). These phenol oxidizing enzymes may participate in plant responses to microbes (Reimers et al., 1992; Chen et al., 2000). However, resistance studies pertaining to Marssonina blotch are rather limited (Sharma and Bhardwaj, 2003). The present study was therefore, undertaken to find out the role of biochemical mechanisms involved in resistance against Marssonina blotch after treatment with induced resistance chemicals.

\section{MATERIALS AND METHODS}

Method of induction: To study the effect of salicylic acid (SA), dipotassium phosphate $\left(\mathrm{K}_{2} \mathrm{HPO}_{4}\right)$ and acibenzolar-S-methyl (ASM) on changes in phenolics, sugars, peroxidase and polyphenol oxidase in apple leaves, of the cultivars Starking Delicious, Tydeman's Early Worcester and Granny Smith apart from disease incidence were sprayed with $100 \mathrm{ppm} \mathrm{SA,} \mathrm{K}_{2} \mathrm{HPO}_{4}$ and ASM 48hrs before inoculation and distilled sterilized water was sprayed on control plants. Inoculum was applied on the test plants by spraying with a standardized spore suspension of $5 \times 10^{4}$ conidia per $\mathrm{ml}$. Pathogen alone inoculated plants served as control. At various time intervals (48, 72 and $96 \mathrm{hrs})$ after treatments, leaf samples were collected and analyzed for different parameters.

Estimation of phenol content: Total phenol content of the apple leaf was estimated by Folin Ciocalteau method (Bray and Thorpe, 1954). One gram of leaf sample was homogenized in $10 \mathrm{ml}$ of 80 per cent ethanol and agitated for 15 minutes at $70^{\circ} \mathrm{C}$; filtered through muslin cloth and again through Whatman No.1 filter paper and the volume of the filtrate were adjusted to $5 \mathrm{ml}$ with 80 per cent ethanol. In a test tube, one $\mathrm{ml}$ of ethanol extract, one $\mathrm{ml}$ of Folin Ciocalteau reagent and $2 \mathrm{ml}$ of $20 \%$ sodium carbonate solution were added and the mixture was heated in a boiling water bath for a minute. Then the tube was cooled under running tap water and final volume was made to $25 \mathrm{ml}$ with distilled water. A reagent blank was maintained with one $\mathrm{ml}$ of distilled water instead of leaf extract. The intensity of colour was recorded at $650 \mathrm{~nm}$ in spectrophotometer. The amount of total phenols present in the sample was calculated from a standard curve prepared by using different concentrations of catechol.

Estimation of reducing and non reducing sugar: Reducing sugars was estimated following Nelson's modification of Somogyi's method (Nelson, 1944). To one $\mathrm{ml}$ of tissue extract in a $25 \mathrm{ml}$ test tube, $1 \mathrm{ml}$ of fresh copper reagent was added. The solutions were mixed and then heated exactly for 20 minutes in a boiling water bath. It was taken out and cooled in a pan of cold water. Thereafter one $\mathrm{ml}$ of arsenomolybdate reagent was added. The contents were mixed thoroughly till the effervescence ceased. The volume was raised to $20 \mathrm{ml}$ with double glass distilled water and intensity of blue colour was measured at $620 \mathrm{~nm}$. The quantity of reducing sugars was calculated from a standard curve prepared with known concentrations of glucose.

Non reducing sugars were determined by hydrolysis of extract i.e. one $\mathrm{ml}$ of the extract was put in $25 \mathrm{ml}$ test tube with $2 \mathrm{ml}$ of $1 \mathrm{~N}$ sulphuric acid. It was heated at $50^{\circ} \mathrm{C}$ for 30 minutes and then cooled in a pan of cold water. Thereafter, 1-2 drops of methyl red indicator solution were added. The reddish solution was then neutralized with $1 \mathrm{~N} \mathrm{NaOH}$, adding it drop by drop. This solution was then treated as in case of reducing sugars for finding out the total sugars present in the sample. By subtracting the reducing sugars from total sugars the non-reducing sugars were calculated.

Peroxidase activity: For peroxidase estimation, three $\mathrm{ml}$ of pyragallol solution was taken in a colorimeter tube, to which $0.1 \mathrm{ml}$ tissue extract was added. The absorbance was adjusted to zero at $420 \mathrm{~nm}$ in Spectronic 20. The tube was then taken out and $0.5 \mathrm{ml}$ of one per cent $\mathrm{H}_{2} \mathrm{O}_{2}$ was added to its contents and mixed by inverting and the tube was again placed in the colorimeter immediately. The changes in absorbance were recorded at 20 seconds interval upto 3 minutes. The change in absorbance between 40 and 160 seconds was used to plot peroxidase activity and results were expressed as change in optical density per gram fresh weight of the material. An increase in absorbance by 0.01 per minute was taken as one unit (Mahadevan and Sridhar, 1982).

Polyphenol oxidase activity: For polyphenol oxidase determination, $2 \mathrm{ml}$ of enzyme source, $3 \mathrm{ml}$ of phosphate buffer was added in a colorimeter tube. The contents were intermixed and placed in a Spectronic 20 set at $495 \mathrm{~nm}$ wavelength. The absorbance was then adjusted to zero. The tube was then taken out and one $\mathrm{ml}$ of $0.01 \mathrm{M}$ catechol was added and the contents were mixed. The tube was again placed in the colorimeter. The change in absorbance was recorded for every 30 seconds upto 3 minutes. Change in absorbance between 30 and 150 seconds was plotted for ployphenol oxidase activity and the results were as change in optical density per gram of the leaf tissues. An increase in the absorbance by 0.01 per minute was taken as one unit (Mahadevan and Sridhar, 1982).

Statistical analysis: Laboratory experiments were analyzed under Completely Randomized factorial Design (CRD) with three replications. Statistical significance of the data was determined using analysis of variance (ANOVA).

\section{RESULTS AND DISCUSSION}

Total phenols: The data on total phenol (Table 1) revealed that all the three test cultivars i.e. Starking Delicious, Tydeman's Early Worcester and Granny Smith differed significantly in their phenol content after treatment with SAR inducer chemicals at three sampling periods viz.(48,72,96 hrs). In cultivar 

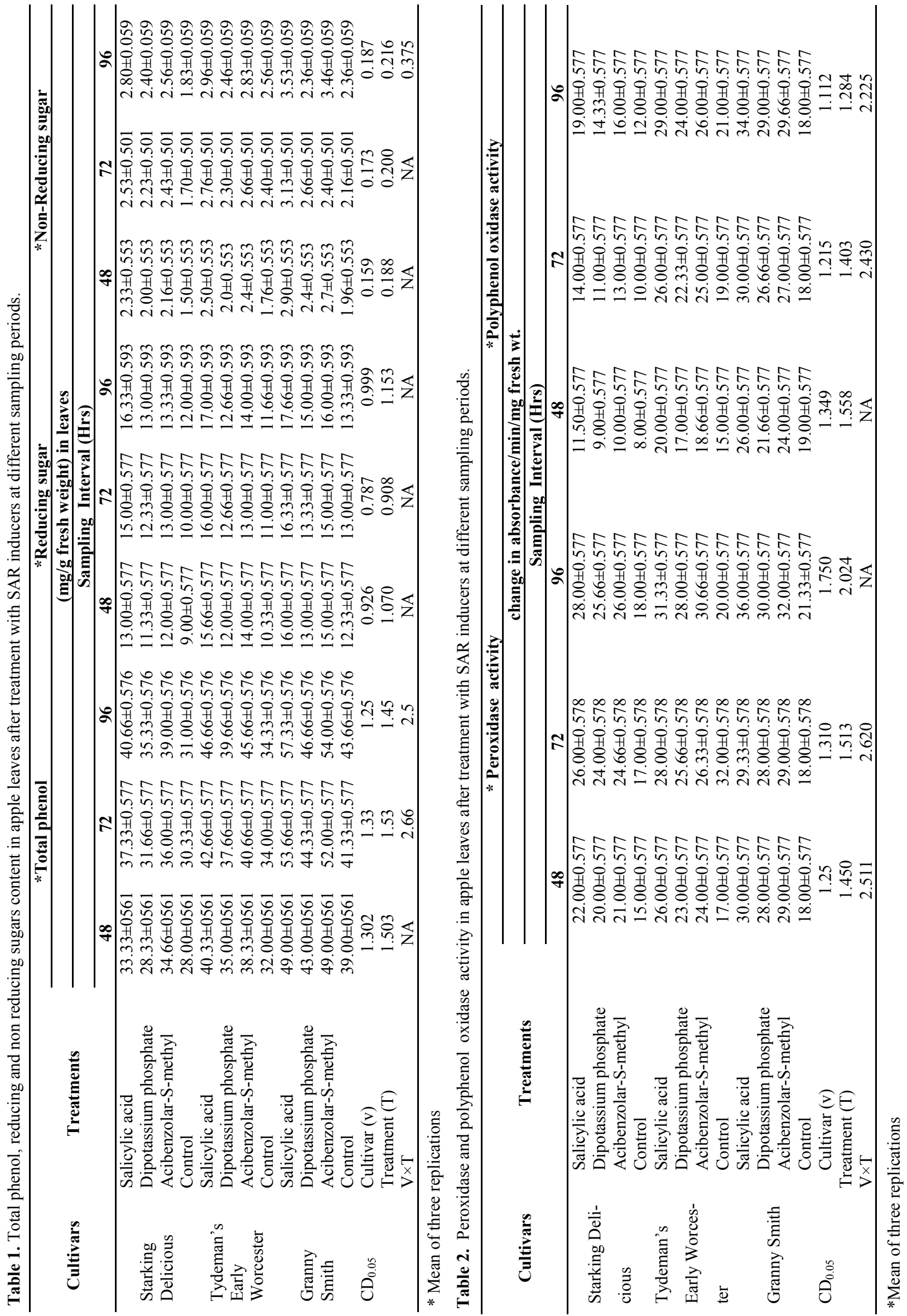
Starking Delicious, SA spray showed the maximum phenol content in all the three sampling periods i.e. $(34.33,37.33,40.66 \mathrm{mg} / \mathrm{g})$ followed by ASM $(33,36$, $39 \mathrm{mg} / \mathrm{g})$ and $\mathrm{K}_{2} \mathrm{HPO}_{4}(28.33,31.66,36 \mathrm{mg} / \mathrm{g})$. Water treated control plants also increased the phenol content but the level was less as compared to SAR inducer treated plant. A similar trend was found in cultivars Tydeman's Early Worcester and Granny Smith, where phenol content was also highest in SA treated plants i.e. $40.33,42.66,46.66 \mathrm{mg} / \mathrm{g}$ and $49,53.66,57.33 \mathrm{mg} /$ $\mathrm{g}$ was followed by ASM treated plant and $\mathrm{K}_{2} \mathrm{HPO}_{4}$ treated plants. Further, when we compared phenol content within cultivars, the phenol content were more in Granny smith and Tydeman's Early Worcester than in the susceptible cultivar Starking Delicious. The data also indicated that all the values were statistically significant among each other. Similar observations on other host-pathogen combinations as influenced by abiotic elicitor treatments have been reported earlier. Phenolic compounds are directly involved in the plant response to disease. As a first line of defence, they are either toxic to pathogens or can be deposited inside the cell walls. Meena et al. (2001) found that salicylic acid applied as pre-inoculation spray in groundnut plants challenge inoculated with Cercosporidium personatum resulted in three fold increases in the phenol content on fourth day. Accumulation of phenolics at the site of infection is a general response of plants in many host pathogen interactions (Farkas and Kiraly, 1962) and this accumulation is fostered by biotic and abiotic elicitors. Vimala et al. (2009) reported that pre-inoculation spray of salicylic acid showed the maxmum phenolic content followed by post-inoculation spray. Resistant and moderately resistant genotypes recorded more phenol content than susceptible ones (Sunkad and Kulkarni, 2006). Sharma (1987) reported that an increase in total phenol content in apple leaves was evident after two days of inoculation (Venturia inaequalis), and being more consipicous in resistant cultivars. Matern and Kneusal (1988) expressed the view that the first stage of defence in plants is the accumulation of phenols at the infection site which restricts the growth of the pathogen.

Reducing and non reducing sugars: Data (Table 1) presented, on reducing sugars assayed at three sampling hours in the test cultivars i.e. Starking Delicious, Tydeman's Early Worcester and Granny Smith pretreated with SAR inducers (SA, ASM and $\mathrm{K}_{2} \mathrm{HPO}_{4}$ ) indicated that SA treated control contained highest amount followed by ASM and $\mathrm{K}_{2} \mathrm{HPO}_{4}$ in all the cultivars as compared to the water treated control. In cultivar Starking delicious, highest amount of reducing sugars was found in SA treated plants (13.00, $15.00,16.33 \mathrm{mg} / \mathrm{g})$ followed by ASM $(12.00,12.33$, $13.00 \mathrm{mg} / \mathrm{g})$ and $\mathrm{K}_{2} \mathrm{HPO}_{4}(11.33,12.33,13.00 \mathrm{mg} / \mathrm{g})$ treated plants. Similarly in other two cultivar Tydeman's Early Worcester and Granny Smith the reducing sugars content was highest in SA treated plants followed by ASM and $\mathrm{K}_{2} \mathrm{HPO}_{4}$ treated plants

The content of non reducing sugars at three sampling hours was higher in SA treated followed by ASM and $\mathrm{K}_{2} \mathrm{HPO}_{4}$ treated plants in all the cultivars pretreated with SAR inducers (SA, ASM and $\mathrm{K}_{2} \mathrm{HPO}_{4}$ ) (Table 1). In cultivar, Starking delicious highest amount of nonreducing sugars was found in SA treated plant (2.33, $2.53,2.80 \mathrm{mg} / \mathrm{g})$ followed by $\operatorname{ASM}(2.16,2.43,2.56$ $\mathrm{mg} / \mathrm{g})$, and $\mathrm{K}_{2} \mathrm{HPO}_{4}(2.00,2.23,2.40 \mathrm{mg} / \mathrm{g})$ compared to water treated control. A Similar trend was found in cultivars Tydeman's Early Worcester and Granny Smith as presented in the data (Table 1). Further the data (Tables1) showed that Granny Smith and Tydeman's Early Worcester cultivars recorded more reducing and non reducing sugars than susceptible cultivar Starking Delicious. Data indicated that all the values are statistically significant among each other. A similar trend of decreased sugar levels in sunflower and betelvine leaves infected with rust and leaf spot bacterium was observed by Prasad et al. (1976) and Nema (1989). The depletion of sugars during host-parasite interaction might be due to increased respiration or utilization of sugars by the fungi which depends on the capability of fungi to secrete carbohydrate degrading enzyme. Nema (1989) suggested that reduction in sugars during disease development might be due to utilization of sugars probably for energy and synthetic reactions involved in multiplication of the pathogen. The results of present findings are in agreement with the findings of Gupta et al. (2010) who observed higher amount of reducing and non-reducing sugars in resistant cultivars of french bean Kentucky Wonder and Pant Anupama than those in the susceptible ones Contendor and Laxmi cultivars against anthracnose caused by Colletotrichum lindemuthianum.

Peroxidase and polyhenol activity: Data pertaining to peroxidase and polyphenol activity (Table 4 and 5) revealed that different cultivars differed significantly in their peroxidase activity at different sampling periods after treatment with SAR chemicals with cultivar Granny Smith showing maximum peroxidase activity in all the three sampling periods highest in SA $(29.33,30,36)(26,30,34)$ treated plants followed by ASM $(28,29,32)(24,27,29.66)$ and $\mathrm{K}_{2} \mathrm{HPO}_{4}(28,28$, 30) $(24,27,29.66)$ treated plants. Water treated control plants also increased the peroxidase activity but the level was less as compared to SAR chemical treated plants. Similar trend was observed in cultivars Tydeman's Early Worcester and Starking Delicious, where peroxidase activity was highest in SA treated plants followed by ASM and $\mathrm{K}_{2} \mathrm{HPO}_{4}$ treated plants. Further on comparison among the cultivars, it was found that the peroxidase activity were more in Granny Smith and Tydeman's Early Worcester than that in the susceptible cultivar Starking Delicious. Data indicated that all the values are statistically significant among each other Increase in the activity of peroxidase and 
polyphenol oxidase in host tissues in response to infection by the pathogen has been reported in many cases (Sharma and Kaul, 1996; Yedidia et al., 1999; Dutta and Chatterjee, 2000; Jose et al., 2001) and is considered to play an active role in contributing to disease resistance in certain host-pathogen interaction following incubation. Peroxidase has antifungal effects and has been implicated in the defence responses to pathogens in various crops. Increase in peroxidase activity has been shown to be associated with lignification, phenol oxidation and plant defence. Peroxidase is a key enzyme in the biosynthesis of lignin and other oxidized phenols (Bruce and West, 1989). Peroxidase and polyphenol oxidase mediate the oxidation of phenols and oxidized phenols are highly toxic to the pathogen (Sequeira, 1983). The results get further support from the findings of Sharma and Kaul (1996) who reported polyphenol oxidase and peroxidase activities varied in young expanding leaves of test resistant and susceptible apple cultivars inoculated with Venturia inaequalis and also showed that the activities of these enzymes increased following inoculation and the leaves of resistant cultivars showed prominent upsurge after 2 days showing highly significant correlation with disease resistance.

\section{Conclusion}

It was concluded that in all the three cultivars viz., Starking Delicious, Tydeman's Early Worcester and Granny Smith after treatment with SAR inducers i.e. salicylic acid (SA), dipotassium phosphate $\left(\mathrm{K}_{2} \mathrm{HPO}_{4}\right)$ and acibenzolar-S-methyl (ASM) ,there was an increased in phenol, reducing sugar, non-reducing sugar content,polyphenol and peroxidase activity over the untreated control and it was recorded maximum in salicylic acid treated leaves and minmum in dipotassium phosphate treated leaves in all the three cultivars. The study showed that application of systemic acquired resistance (SAR) chemical can induce resistance in apple plants against Marssonina blotch caused by $M$. coronaria showing strong correlation between the ability of elicitors to enhanced plant disease resistance and elicitation of defence related enzymes and may also provide a practical supplement to environmentally- friendly disease management options when they are combined with appropriate integrated agronomic practices.

\section{REFERENCES}

Bray, H.G and Thorpe, W.V. (1954). Analysis of phenolic compounds of interest in metabolism. Methods in Biochemistry Analysis, 1: 27-52.

Bruce, R.J. and West C.A. (1989). Elicitation of lignin biosynthesis and isoperoxidase activity of (Cucumis sativus L.) by the biocontrol agent T.harzianum. Applied and Environment Microbiology, 65(3):10611070.

Chen, C., Belanger, R.R., Benhamou, N. and Paulitz, T.C. (2000). Defense enzymes inducedin cucumber roots by treatment with plant growth-promoting rhizobacteria (PGPR) and Pythium aphanidermatum. Physiology and Molecular Plant Pathology, 56:13-23.

Dao, T.T.H., Linthorst, H.J.M. and Verpoorte, R. (2011). Chalcone synthase and its functionsin plant sresistance. Phytochemistry Reviews, 10: 397-412.

Delaney, T.P., Friedrich, L. and Ryals, J.A. (1995). Arabidopsis signal transduction mutant defective in chemically and biologically induced disease resistance. Proceeding of National Academy of Sciences USA, 92:6602 - 6606.

Dutta, S. and Chatterjee, N.C. (2000). Peroxidase activity vis -à-vis resistance to Rhizopus rot of infected with Phaeomoniella chlamydospora and Phaeoacremonium species. Indian Biologist, 32(2): 61-63.

Farkas, G. and Kiraly, J. (1962). Role of phenolic compounds in the physiology of plant disease and disease resistance. Phytopathological Zoology, 44: 105-150.

Gupta Sachin, Mallick, S. A and Gupta Moni. 2010. Role of oxidative enzymes and biochemical constituents in imparting resistance to french bean varieties against bean anthracnose. Indian Phytopathology 63 (1): 47-50.

Harada, Y., Sawamura, K. and Konno, K. (1974). Diplocarpon mali, sp.nov, the perfect state of apple blotch fungus Marssonina coronaria. Annual Phytopathological Society of Japan, 40:412 - 418.

Jose, A, Del Rio, Ana Gonzalez, Maria D. Fuster, Juana M. Botia, Pedro Gomez, Victor Frias and Ana Ortuno. (2001). Tylose formation and changes in phenolic compounds of grape roots infected with Phaeomoniella chlamydospora and Phaeoacremonium species. Phytopathologia Mediterranean, 40: S394-S399.

Lee Dong-Hyuk, Chang-Gi Back, Nang Kyu Kyu Win, Kyung-Hee Choil, Kyung-Min Kim, In-Kyu Kang,Cheol Choi, Tae-Myung Yoon, Jae Youl Uhm and Hee-Young Jung. (2011). Biological Characterization of Marssonina coronaria Associated with Apple Blotch Disease. Mycriobiology, 39:200-205.

Mahadevan, A. and Sridhar, R. (1982). Methods in physiological Plant Pathology. Shivakami Publications, Madras.

Maleck, K., Levine. A. and Eulgem T. (2000). The transcriptome of Arabidopsis thaliana during systemic acquired resistance. Nature Genetics 26: 403-410. Matern, U. and Kneusal, R.E.(1988). Phenolic compounds in plant disease resistance. Phytoparasitica 16: 153-170.

Meena, B., Marimuthu, T. and Velazhahan, R.( 2001). Salicylic acid induces systemic resistance in groundnut against late leaf spot caused by Cercosporidium personatum. Journal of Mycology and Plant Pathology 31: 139-145.

Mohammadi, M. and Kazemi, H. (2002). Changes in peroxidase and polyphenol oxidase activities in susceptible and resistant wheat heads inoculated with Fusarium graminearum and induced resistance. Plant Science 162: 491-498.

Nelson, N. (1944). A photometric adaptation of the Somogyi method for the determination of glucose. Journal of Biochemistry, 153: 375-380.

Nema A G.(1989). Sugar and phenol contents of betelvine leaves after inoculation with leaf spot bacterium. Indian Phytopathology 42 (1): 31-37.

Nicholson, R.L., Hammerschmidt, R.(1992). Phenolic compounds and their role in disease resistance. Annual Review of Phytopathology, 30:369-389. 
Prasad O. P, Verma S and Daftari L. N. 1976. Biochemical changes in safflower leaves caused by rust infection. Indian Phytopathology 29 (1): 53-5.

Reimers, P.J., Guo, A. and Leach, J.E. (1992). Increased activity of a cationic peroxidase associated with an incompatible interaction between Xanthomonas oryzae pv. oryzae and rice (Oryza sativa). Plant Physiology, 99:1044-1050.

Sequeira L. (1983). Mechanism of induced resistance in plants. Annual Review of Microbiology, 37:51-79.

Sharma, J. N. 1987.Structural and biochemical nature of resistance in apple to Venturia inaequalis.Ph.D. Thesis. Dr. Y.S. Parmar University of Horticulture and Forestry, Nauni, Solan. 158p.

Sharma, J. N. and Bhardawaj S. S. ( 2003). Efficacy and Economics of different fungicide spray schedule in controlling premature leaf fall of apple. Plant Disease Research, 18:21-24.

Sharma,J.N. and Kaul.(1996).Biochemical nature of resistance in apple to Venturia inaequalis causing scab IV. oxidative enzymes. International Journal Of Tropi- cal Plant Diseases.14:173-176

Sharma, J. N .and Gautam, D. R. (1997). Studies on premature leaf fall of apple -a new problem. Journal of Plant Protection 25:8-12.

Slatnar, A., Mikulic Petkovsek, M., Halbwirth, H., Stampar, F., Stich, K. and Veberic, R.(2010). Enzyme activity of the phenylpropanoid pathway as a response to apple scab infection. Annals of Applied Biology 156: 449456.

Soliva, R.C., Elez, P., Sebastian, M. and Martin, O.(2001). Evaluation of browning effect on avocado puree preserved by combined methods. Innovative Food Science and Emerging Technology 1: 261-268.

Vimala, R.and Suriachandraselvan, M. (2009). Induced resistance in bhendi against powdery mildew by foliar application of salicylic acid. Journal of Biopesticides 2 (1): 111-114.

Yedidia, I., Benhamou and Chet, I. (1999). Induction of defence responses in cucumber plants (Cucumis sativus L.) by the biocontrol agent T.harzianum. Applied and Environment Microbiology, 65(3):10611070. 